\title{
A high-density genetic map for anchoring genome sequences and identifying QTLs associated with dwarf vine in pumpkin (Cucurbita maxima Duch.)
}

Guoyu Zhang ${ }^{1+}$, Yi Ren ${ }^{1+}$, Honghe Sun ${ }^{1,2}$, Shaogui Guo ${ }^{1}$, Fan Zhang ${ }^{1}$, Jie Zhang ${ }^{1}$, Haiying Zhang ${ }^{1}$, Zhangcai Jia', Zhangjun $\mathrm{Fei}^{2,3}$, Yong $\mathrm{Xu}^{1 *}$ and Haizhen $\mathrm{Li}^{1^{*}}$

\begin{abstract}
Background: Pumpkin (Cucurbita maxima Duch.) is an economically important crop belonging to the Cucurbitaceae family. However, very few genomic and genetic resources are available for this species. As part of our ongoing efforts to sequence the pumpkin genome, high-density genetic map is essential for anchoring and orienting the assembled scaffolds. In addition, a saturated genetic map can facilitate quantitative trait locus (QTL) mapping.

Results: A set of $186 \mathrm{~F}_{2}$ plants derived from the cross of pumpkin inbred lines Rimu and SQ026 were genotyped using the genotyping-by-sequencing approach. Using the SNPs we identified, a high-density genetic map containing 458 bin-markers was constructed, spanning a total genetic distance of 2,566.8 cM across the 20 linkage groups of $C$. maxima with a mean marker density of $5.60 \mathrm{cM}$. Using this map we were able to anchor 58 assembled scaffolds that covered about $194.5 \mathrm{Mb}(71.7 \%)$ of the $271.4 \mathrm{Mb}$ assembled pumpkin genome, of which 44 (183.0 Mb; $67.4 \%$ ) were oriented. Furthermore, the high-density genetic map was used to identify genomic regions highly associated with an important agronomic trait, dwarf vine. Three QTLs on linkage groups (LGs) 1, 3 and 4, respectively, were recovered. One QTL, aCmB2, which was located in an interval of $0.42 \mathrm{Mb}$ on LG 3, explained $21.4 \%$ phenotypic variations. Within qCmB2, one gene, Cma_004516, encoding the gibberellin (GA) 20-oxidase in the GA biosynthesis pathway, had a 1249-bp deletion in its promoter in bush type lines, and its expression level was significantly increased during the vine growth and higher in vine type lines than bush type lines, supporting Cma_004516 as a possible candidate gene controlling vine growth in pumpkin.

Conclusions: A high-density pumpkin genetic map was constructed, which was used to successfully anchor and orient the assembled genome scaffolds, and to identify QTLs highly associated with pumpkin vine length. The map provided a valuable resource for gene cloning and marker assisted breeding in pumpkin and other related species. The identified vine length QTLs would help to dissect the underlying molecular basis regulating pumpkin vine growth.
\end{abstract}

Keywords: High-density genetic map, Pumpkin (Cucurbita maxima Duch.), Scaffold anchoring, QTL mapping, Dwarf vine

\footnotetext{
* Correspondence: xuyong@nercv.org; lihaizhen@nercv.org

${ }^{\dagger}$ Equal contributors

${ }^{1}$ Beijing Vegetable Research Center, BAAFS, Key Laboratory of Biology and

Genetic Improvement of Horticultural Crops (North China), Ministry of

Agriculture, Beijing Key Laboratory of Vegetable Germplasm Improvement,

Beijing 100097, P.R. China

Full list of author information is available at the end of the article
}

\section{) Biomed Central}

C 2015 Zhang et al. Open Access This article is distributed under the terms of the Creative Commons Attribution 4.0 International License (http//creativecommons.org/licenses/by/4 o/ which permits unrestricted use, distribution, and reproduction in any medium, provided you give appropriate credit to the original author(s) and the source, provide a link to the Creative Commons license, and indicate if changes were made. The Creative Commons Public Domain Dedication waiver (http://creativecommons.org/publicdomain/zero/1.0/) applies to the data made available in this article, unless otherwise stated. 


\section{Background}

Cucurbita maxima including pumpkin, hubbard, turban and buttercup squash, is native to South America and belongs to the genus Cucurbita L. with $n=20$ chromosomes [1]. Pumpkin is one of the most economically important crops within this species [2], and commonly known as winter squash with its mature fruits consumed as vegetables in most of the world, especially in Asia (primarily China and India) and Africa. Even in developing countries, pumpkin is a staple food and a rich source of fat, iron, calcium and vitamins [3]. In addition, pumpkin seeds are also used as food, because they are excellent sources of proteins (32-44\%), oil (34-50\%, over $70 \%$ of unsaturated fatty acids comprised mainly by linoleic and oleic acids) and vitamin $\mathrm{E}[4,5]$. The interspecific hybrids of $C$. maxima $\times C$. moschata are important rootstocks of cucumber and watermelon to increase crop disease resistance, stress-tolerance and yield, and improve fruit quality [6-8].

Despite its economic importance, there are very limited genomic and genetic resources available for C. maxima; unlike other cucurbits, such as cucumber, watermelon and melon, even C. pepo and C. moschata, for which dense genetic maps [9-14], microarrays [15, 16], reverse genetic platforms [17-19], transcriptomes [20-25] and even whole genome sequences [26-28] have been developed and generated. These resources have provided powerful tools for genetic and genomic analysis in exploring gene functions and genetic diversities, and facilitating classical linkage mapping and association mapping, and breeding new varieties [29-36].

Saturated genetic linkage maps are critical for assembled genome scaffold anchoring and orienting, quantitative trait locus (QTL) mapping and efficient molecular breeding $[11,37]$. However, genetic mapping of C. maxima is still in its infancy, with only three low-resolution genetic maps reported [38-40]. Recent advancements in highthroughput genotyping technologies, such as genotypingby-sequencing (GBS) [41], have provided rapid, efficient and cost-effective genotyping approaches, which have proven their efficiency in saturated genetic map construction and gene/QTL mapping in a variety of different species [42, 43].

Dwarf vine is an important agronomic trait targeted for selection in pumpkin breeding due to its contribution to yield and labor-saving in management and harvesting. In tropical pumpkin (C. moschata Duch.) and squash ( $C$. pepo L.), the bush type (dwarf vine) is controlled by a dominant gene, and some bush-type related genes and tightly linked markers have been reported [44-50]. In $C$. maxima, the dwarf vine is possibly mainly controlled by two recessive genes which are orthologous to the dwarf genes in $C$. pepo, and might also be regulated by other minor genes $[51,52]$. Recently, a C. maxima dwarf mutant was reported and the underlying gene was roughly mapped using AFLP markers to a region with a genetic distance of $11.2 \mathrm{cM}$ [53]. Four dwarf-related transcript derived fragments (TDFs), which were involved in cytokinin or indole acetic acid signaling, were identified [53]. The genes controlling dwarf traits in other Cucurbitaceae crops such as melon and cucumber have also been fine mapped recently [30, 54]. Although many studies have been reported on dwarf traits in Cucurbitaceae, to date no dwarf genes have been cloned.

In this study, a C. maxima population with $186 \mathrm{~F}_{2}$ individuals was generated from a cross between an inbred line with long vine (vine type), Rimu, and a line with dwarf vine (bush type), SQ026. The vine length in the $F_{2}$ population showed a continuous phenotypic variation. The vine length trait was found to be quantitative in nature and the dwarf-type was gibberellin-responsive. The population was then genotyped using the GBS approach, resulting in a total of 458 recombinant bin markers, which were used to create the first high resolution genetic map in C. maxima that comprised 20 linkage groups. The map was further used to assist in anchoring and orienting the assembled C. maxima genome scaffolds. Moreover, the vine length was measured for individual plants in the $\mathrm{F}_{2}$ population and an association analysis was then performed to identify QTLs for the dwarf vine trait. The high-density genetic map we constructed provided an invaluable new tool for genetic research and molecular breeding in C. maxima.

\section{Results}

Sequencing, genotyping, and genetic map construction Two 96-plex GBS libraries were constructed for the two parents (two replicates for each) and $186 \mathrm{~F}_{2}$ plants of the cross Rimu $\times$ SQ026. A total of 418 million cleaned reads were obtained, and the number of reads per sample ranged from 0.45 to 4.50 million, with an average of 2.22 million reads for each individual, which was equivalent to $\sim 0.61$-fold coverage of the $C$. maxima genome which was estimated to have a size of approximately 373.9 Mb based on the k-mer analysis of the large-scale Illumina genome sequences. Of these reads, 394.57 million (94.4\%) were mapped to the C. maxima genome assembly and used for SNP calling. The resulting SNPs were filtered if there was no homozygous variation found between the two parents. A total of 8,660 SNPs were obtained, among which 1,881 SNPs had less than $20 \%$ missing data and a minimum allele frequency $(\mathrm{MAF}) \geq 0.2$. These 1,881 segregating SNPs were used for genetic linkage map construction and scaffold anchoring, which yielded a genome-wide SNP density of $\sim 1 \mathrm{SNP} / 144.3 \mathrm{~kb}$.

Due to the relatively small size of the mapping population $(n=186)$, many of the 1,881 SNPs co-segregated in the $F_{2}$ population, suggesting that these loci were in close 
proximity and had not been resolved by recombination events. Therefore, these SNPs were further concatenated into 466 bin markers, with SNPs in one bin considered as a single haplotype. Finally, a total of 458 of the 466 bin-markers were mapped to create the 20 linkage groups (LGs) that corresponded to the 20 chromosomes of pumpkin, with a mean of 22.9 markers per LG. The LGs had an estimated total genetic length of 2,566.8 cM and an average of approximately $5.60 \mathrm{cM}$ per bin (Fig. 1, Additional file 1: Figure S1). The distance between neighboring bin markers ranged from $0.05 \mathrm{cM}$ to $44.89 \mathrm{cM}$. Based on the estimated size of the pumpkin genome $(373.9 \mathrm{Mb})$, the map defined herein represented an average physical interval of $816.4 \mathrm{~Kb}$ per marker, making it the most saturated genetic map of $C$. maxima to date. The size of LGs ranged from $47.6 \mathrm{cM}$ (LG 10) to $268.0 \mathrm{cM}$ (LG 4) with the number of bin markers per LG ranging from 10 to 41 . In this map eight large gaps ( $\geq 18 \mathrm{cM}$ ) between scaffolds in LGs $2,3,6,7,11,15$, and 19 were detected (Fig. 1).

Segregation distortion plays a dominant part in the plant genome evolution [55]. In our map two segregation distortion regions (SDRs) were detected in LGs 3 and 12, respectively $(P<0.05)$ (Additional file 2 : Table $S 1)$. The SDR in LG 12 spanned relatively large fraction of the LG, from 0.6 to $16.4 \mathrm{cM}$ (Fig. 1), with marker alleles associated with the Rimu parent. Marker alleles within the SDR of LG 3 skewed toward the SQ026 parent.

\section{Scaffold anchoring and orienting}

The map was further used to anchor and orient the assembled genome scaffolds of the maternal parent of the $\mathrm{F}_{2}$ population, Rimu, to the 20 LGs. Altogether, 58 scaffolds with a total length of $194.5 \mathrm{Mb}$, accounting for $71.7 \%$ of the assembled $271.4 \mathrm{Mb}$ sequences were successfully anchored (Table 1, Fig. 1). The number of scaffolds anchored per LG ranged from 1 (LG10) to 7 (LG6) with sizes ranging from 6.34 $\mathrm{Mb}$ (LG10) to $17.91 \mathrm{Mb}$ (LG4). On average, each scaffold contained eight markers, and 44 scaffolds $(183.03 \mathrm{Mb} ; 67.4 \%$ of the assembled scaffolds) were anchored by at least two different markers, which could be oriented with high confidence on the genetic map (Table 1, Fig. 1). For the remaining 14 smaller scaffolds (most of them less than $1.5 \mathrm{Mb}$ and a total of $11.5 \mathrm{Mb}$ ) that had only one genetic marker, their orientation on the map could not be

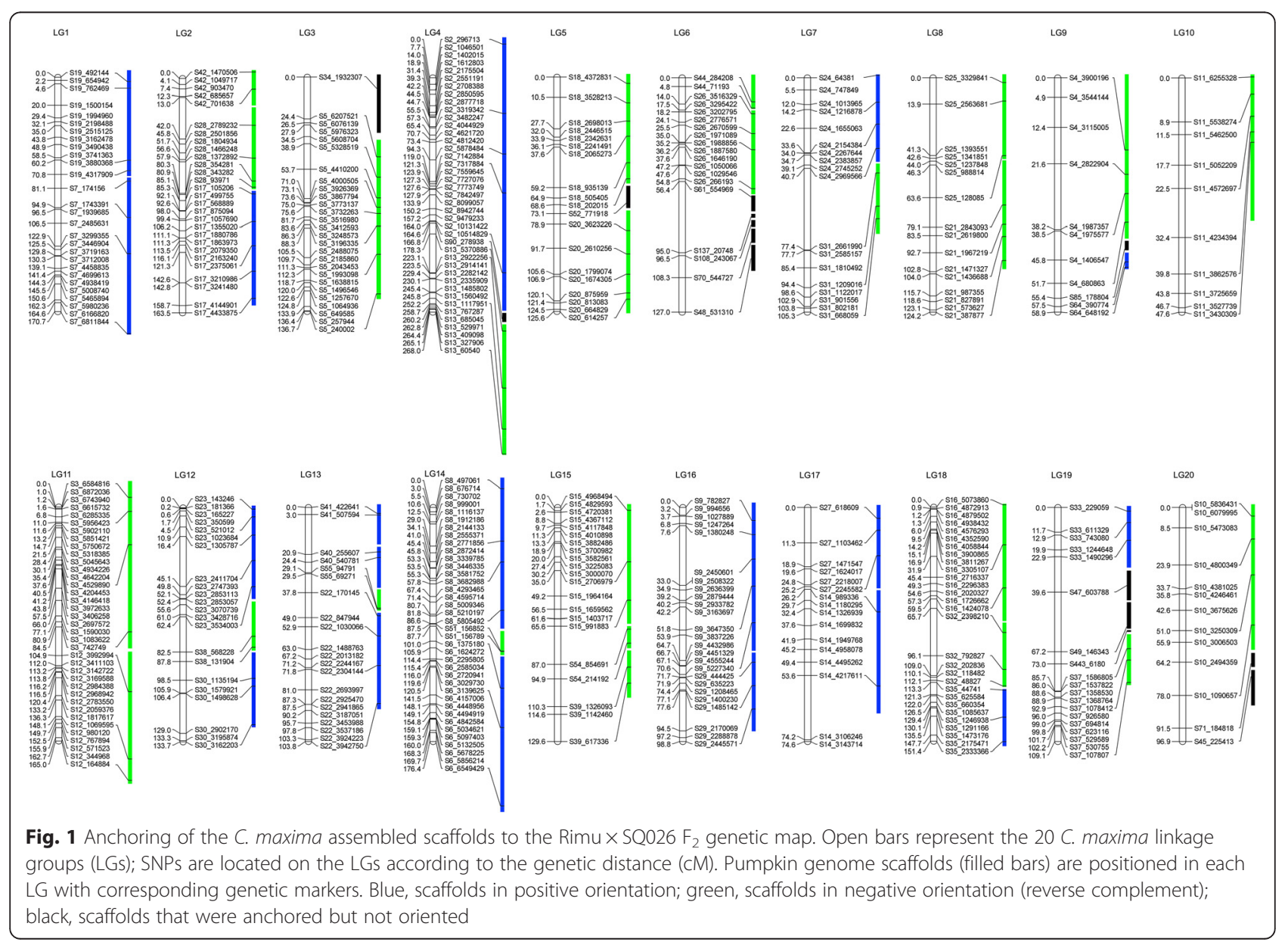


Table 1 Anchoring of C. maxima genome assembly to the genetic map

\begin{tabular}{|c|c|c|c|c|c|c|c|}
\hline LG & LG size $(\mathrm{cM})$ & $\begin{array}{l}\text { No. anchored } \\
\text { scaffolds }\end{array}$ & $\begin{array}{l}\text { Anchored scaffold } \\
\text { size }(\mathrm{Mb})\end{array}$ & $\%$ of assembly & $\begin{array}{l}\text { No. oriented } \\
\text { scaffolds }\end{array}$ & $\begin{array}{l}\text { Oriented scaffold } \\
\text { size }(\mathrm{Mb})\end{array}$ & $\begin{array}{l}\text { Recombination } \\
\text { rate (cM/Mb) }\end{array}$ \\
\hline 1 & 170.74 & 2 & 11.41 & 4.20 & 2 & 11.41 & 14.96 \\
\hline 2 & 163.50 & 3 & 10.10 & 3.72 & 3 & 10.10 & 16.19 \\
\hline 3 & 136.74 & 2 & 9.42 & 3.47 & 1 & 6.89 & 19.85 \\
\hline 4 & 268.01 & 3 & 17.91 & 6.60 & 2 & 17.52 & 15.30 \\
\hline 5 & 125.60 & 3 & 10.10 & 3.72 & 2 & 9.12 & 13.77 \\
\hline 6 & 126.97 & 7 & 8.03 & 2.96 & 2 & 5.19 & 24.46 \\
\hline 7 & 105.35 & 2 & 6.84 & 2.52 & 2 & 6.84 & 15.40 \\
\hline 8 & 124.16 & 2 & 7.92 & 2.92 & 2 & 7.92 & 15.68 \\
\hline 9 & 58.93 & 3 & 8.25 & 3.04 & 2 & 7.83 & 7.53 \\
\hline 10 & 47.61 & 1 & 6.34 & 2.34 & 1 & 6.34 & 7.51 \\
\hline 11 & 164.98 & 2 & 12.97 & 4.78 & 2 & 12.97 & 12.72 \\
\hline 12 & 133.66 & 3 & 9.42 & 3.47 & 3 & 9.42 & 14.19 \\
\hline 13 & 103.82 & 4 & 8.50 & 3.13 & 4 & 8.50 & 12.21 \\
\hline 14 & 176.36 & 3 & 14.49 & 5.34 & 3 & 14.49 & 12.17 \\
\hline 15 & 129.60 & 3 & 8.17 & 3.01 & 3 & 8.17 & 15.86 \\
\hline 16 & 98.78 & 2 & 9.82 & 3.62 & 2 & 9.82 & 10.06 \\
\hline 17 & 74.59 & 2 & 8.98 & 3.31 & 2 & 8.98 & 8.31 \\
\hline 18 & 151.41 & 3 & 10.26 & 3.78 & 3 & 10.26 & 14.76 \\
\hline 19 & 109.07 & 5 & 7.36 & 2.71 & 2 & 4.92 & 22.17 \\
\hline 20 & 96.94 & 3 & 8.24 & 3.04 & 1 & 6.34 & 15.29 \\
\hline Total & 2566.82 & 58 & 194.53 & 71.67 & 44 & 183.03 & 13.19 \\
\hline
\end{tabular}

determined. Although the average marker distance was $424.7 \mathrm{~kb}$, large gaps were present on the physical map, e.g., a 2.4-Mb gap in scaffold S13 on LG 4 between S13_5370886 and S13_2922256 and a 1.6-Mb gap in scaffold S32 on LG 18 between S32_792827 and S32_2398210.

\section{QTL identification for dwarf vine}

The maternal line Rimu and the male parent SQ026 had mean vine length of $256 \mathrm{~cm}$ and $73 \mathrm{~cm}$ at the 25th internode, respectively, and the $F_{1}$ plants presented an intermediate vine length of $154 \mathrm{~cm}$ (Fig. 2, Additional file 2: Table S2). The dwarf SQ026 plants produced shorter vines, as well as fewer and shorter internodes than the vine type Rimu and $F_{1}$ plants at 30th and 60th day after sowing (DAS) (Fig. 2f-h). Transgressive segregation was observed in the $F_{2}$ population for vine length and the average value skewed toward the long vine parent. Frequency distribution of vine length among the test lines is presented in Additional file 1: Figure S2. Using joint analysis (LOD $\geq 4$ ), three QTLs associated with dwarf vine were detected on LGs 1 ( $q C m B 1)$, 3 ( $q C m B 2)$, and $4(q C m B 3)$, respectively (Table 2, Fig. 3), with additive effects ranging from 26.67 to 44.40 and $\mathrm{R}^{2}$ values from 7.65 to $21.39 \%$. As expected, the elite parental cultivar (SQ026) contributed the dwarf vine alleles at all loci. $q C m B 2$, the QTL with the largest effect on vine length, explained $21.39 \%$ of the phenotypic variation and mapped to a region between S5_1064936 and S5_649586, which spanned a genetic distance of about $9.1 \mathrm{cM}$ and corresponded to a physical distance of about $0.42 \mathrm{Mb}$ (Fig. 3). The other two minor QTLs explained 7.65 and $9.95 \%$ of the phenotypic variation, respectively. In addition, when the $F_{2}$ individuals were arbitrarily divided into three groups with short, median and long vines, these three QTLs could still be identified based on a permutation determined LOD threshold of 4.

\section{A candidate gibberellin biosynthesis gene in the major QTL region controlling vine length}

The small physical interval of $q C m B 2(\sim 0.42 \mathrm{Mb}$ in length defined by bin-makers S5_1064936 and S5_649585) encompassed 104 predicted protein-coding genes (Additional file 2: Table S3). Many studies have shown that most dwarf or semi-dwarf type varieties were caused by the deficiency of genes involved in the gibberellin (GA) biosynthesis or signaling [56-59]. The dwarf lines in C. maxima were GA-sensitive as their vine length was increased significantly after treated with GA (Additional file 1: Figure S3). Among 


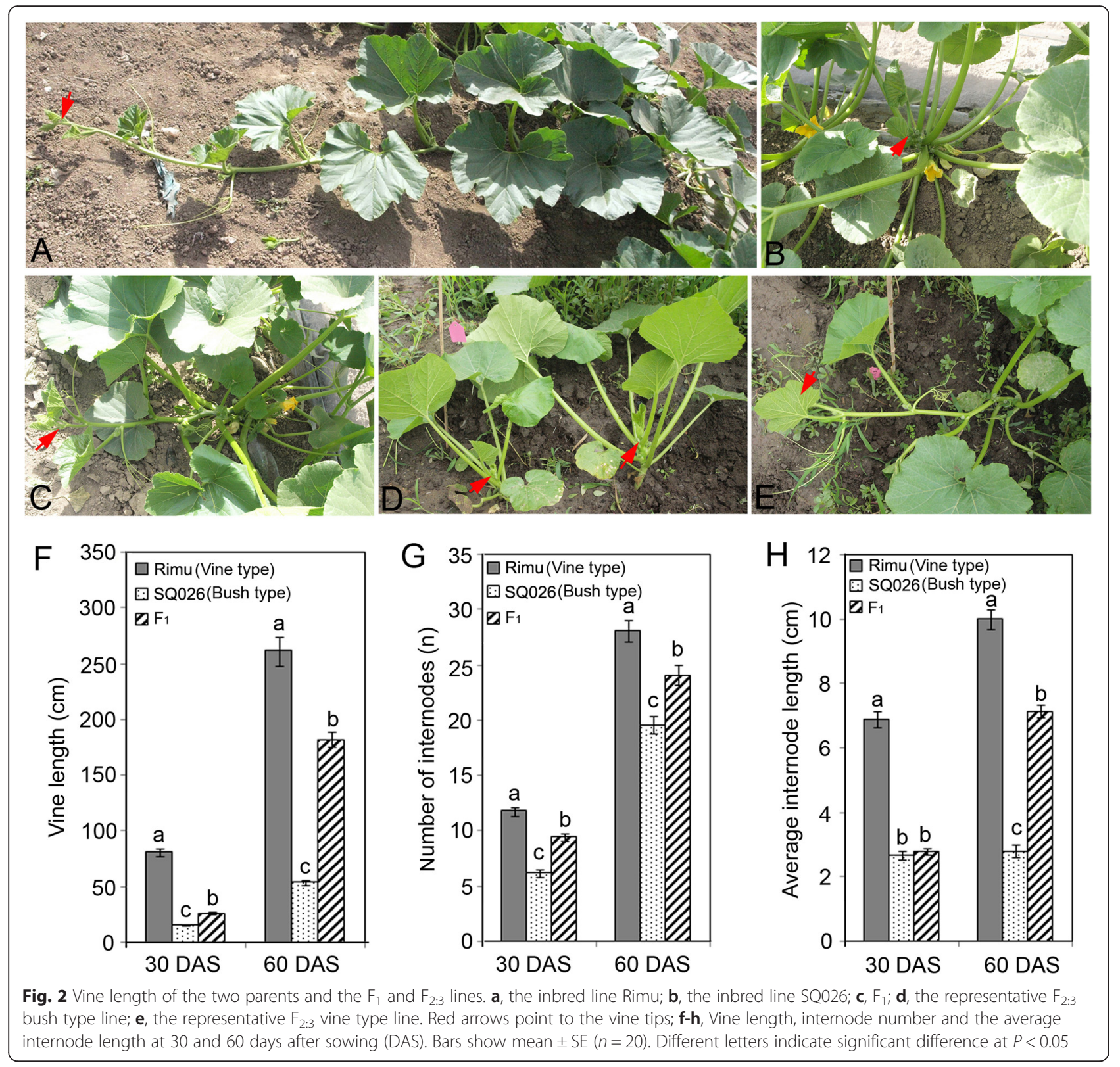

the genes in the genomic region of $q \mathrm{CmB2}$, three genes (Cma_004514,Cma_004515 and Cma_004516) encoding 2-oxoglutarate (2OG) and Fe(II)-dependent dioxygenase superfamily proteins, which are possibly involved in the GA biosynthesis [60,61], were identified. We then performed genome resequencing for the male parent, SQ026, and obtained a total of 321.6 million paired-end reads with length of $100 \mathrm{bp}$. By aligning these reads to the assembled genome of Rimu, the maternal parent, we identified a 1,249-bp insertion/deletion (InDel) (Additional file 1: Figure S4) and two SNPs in the promoter region and a 3-bp InDel and 8 SNPs in the intronic

Table 2 QTL analysis for dwarf vine in C. maxima

\begin{tabular}{lllcllcrrrr}
\hline Trait & QTL & LG. & Position (cM) & Left Marker & Right Marker & Physical length (Mb) & LOD score & PVE (R \%) & Add & Dom \\
\hline VL & qCmB1 & 1 & 142.0 & S7_4699613 & S7_4938419 & 0.24 & 6.07 & 9.95 & 30.33 & -4.41 \\
& qCmB2 & 3 & 125.0 & S5_1064936 & S5_649585 & 0.42 & 12.24 & 21.39 & 44.40 & -1.80 \\
& qCmB3 & 4 & 2.0 & S2_296713 & S2_1046501 & 0.75 & 4.60 & 7.65 & 26.67 & -3.81
\end{tabular}

VL vine length, PVE percentage of the phenotypic variation explained by the QTL; Add, positive values of the additive effect indicated that alleles from SQ026 were in the direction of increasing trait score; Dom dominant effects 


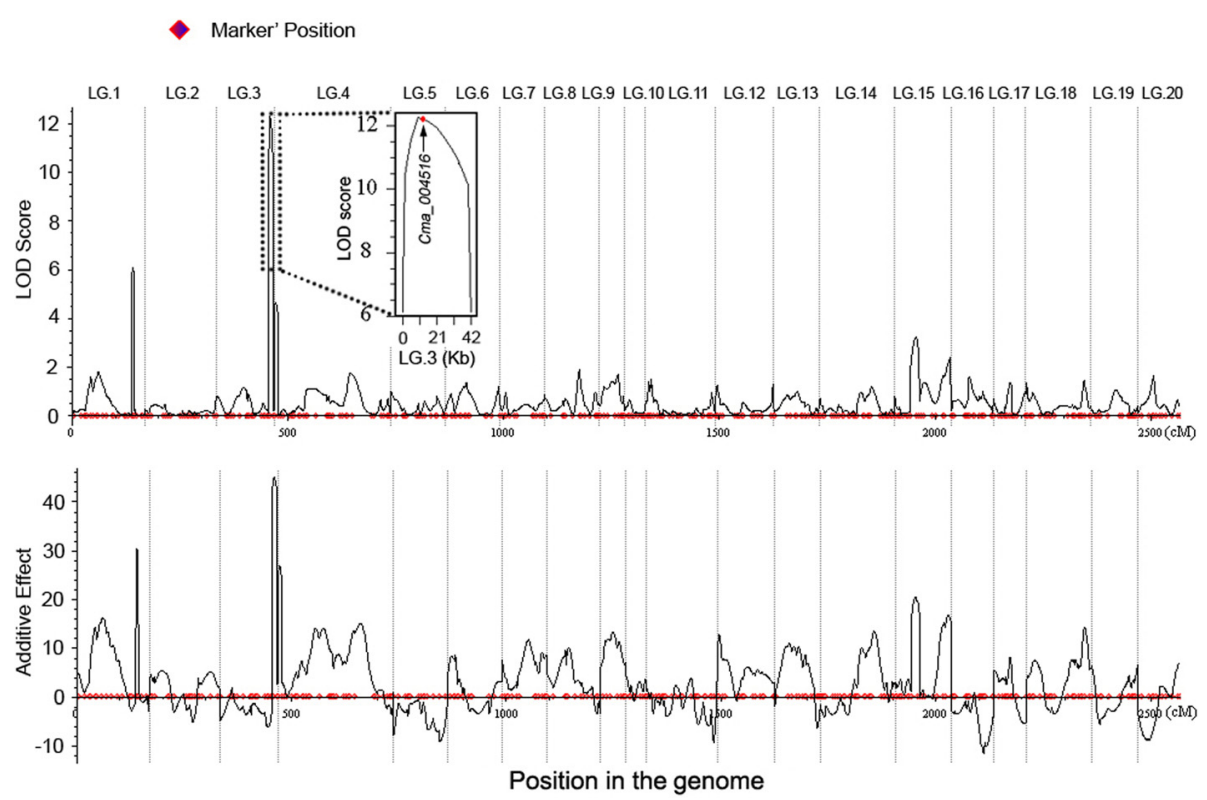

Fig. 3 Mapping of QTLs controlling vine length in the $F_{2}$ population and the location of $q C \mathrm{CmB2}$. Curves in plot indicate the genetic coordinate and LOD score (top) or additive effect (bottom) of detected QTLs. The box inside shows the zoom-in view of the peak on LG 3. Red dot indicates the physical position of the gene Cma_004516

region of Cma_004516 (Additional file 1: Figure S5). These sequence variations were further verified by PCR cloning and sequencing. Two PCR-based molecular markers targeting this 1,249-bp InDel, named InDel1456 and InDel1146, were developed (Fig. 4a). All $\mathrm{F}_{2}$ individuals were genotyped using these two markers (Fig. 4b), and the 1,249-bp InDel polymorphism was found to completely co-segregate with the dwarf vine in the $F_{2}$ and the $F_{2: 3}$ populations without any recombinants (Additional file 2: Table S4 and S5). Validation of this InDel polymorphism in 164 pumpkin varieties which are either bush or vine habits showed that the marker could accurately identify the phenotypes (Additional file 2: Table S6). The physical position of the Cma_004516 gene in the pumpkin genome is 764,230-765,689 bp on the Scaffold S5, which is very close to the peak of LOD curve for the vine length QTL $q C m B 2$ (Fig. 3).

We further investigated the expression pattern of Cma_004516 with semi-quantitative PCR and GPCR in two parental lines to check whether the expression level was affected by the sequence deletion in the promoter region and contributed to the variance of vine length (Fig. 5a and b). The Cma_004516 transcripts were highly abundant in elongated vines (60 days after sowing) and flowers (in SQ026), also present in leaves and tips of the vines, and almost undetectable in roots and fruits. The expression level of Cma_004516 was significantly increased during the vine elongating process (from 20 to 60 days after sowing), and was significantly higher in the vine type lines than in the bush type lines $(p<0.05)$
(Fig. $5 \mathrm{a}$ and $\mathrm{b})$. In transient expression assays, the activity of the promoter of Cma_004516 in bush type line was much weaker than that in the vine type line (Fig. 5c). The expression of another GA 20-oxidase gene in the region of $q \mathrm{CmB2}$, Cma_004514, was restricted to roots, and another gene, Cma_004515, was expressed at the similar level in all tested tissues.

Phylogenetic analysis showed that Cma_004516 was the ortholog of MtGA20ox1-B, the gibberellin 20 oxidase 1-B gene in Medicago truncatula (Additional file 1: Figure S6), suggesting Cma_004516 is a possible enzyme that catalyzes the last three steps of the synthesis of active GAs in C. maxima. All data present here provides evidences supporting that Cma_004516 could be a candidate gene controlling vine length in C. maxima.

\section{Discussion}

In this study, we described the construction of the first high-density genetic map in C. maxima using the bin-markers developed using the GBS technology. This linkage map was further used as a reference to successfully anchor and orient the full genome assembly and to map QTLs for dwarf vine in this species. This map will be valuable for future gene cloning, QTL mapping and marker assisted breeding, and provide a basis for comparative analysis among cucurbit genomes. In addition, the identified QTLs for dwarfism also provide a solid foundation for the characterization of the dwarf gene and uncovering the molecular mechanisms of the dwarfism in pumpkin. 


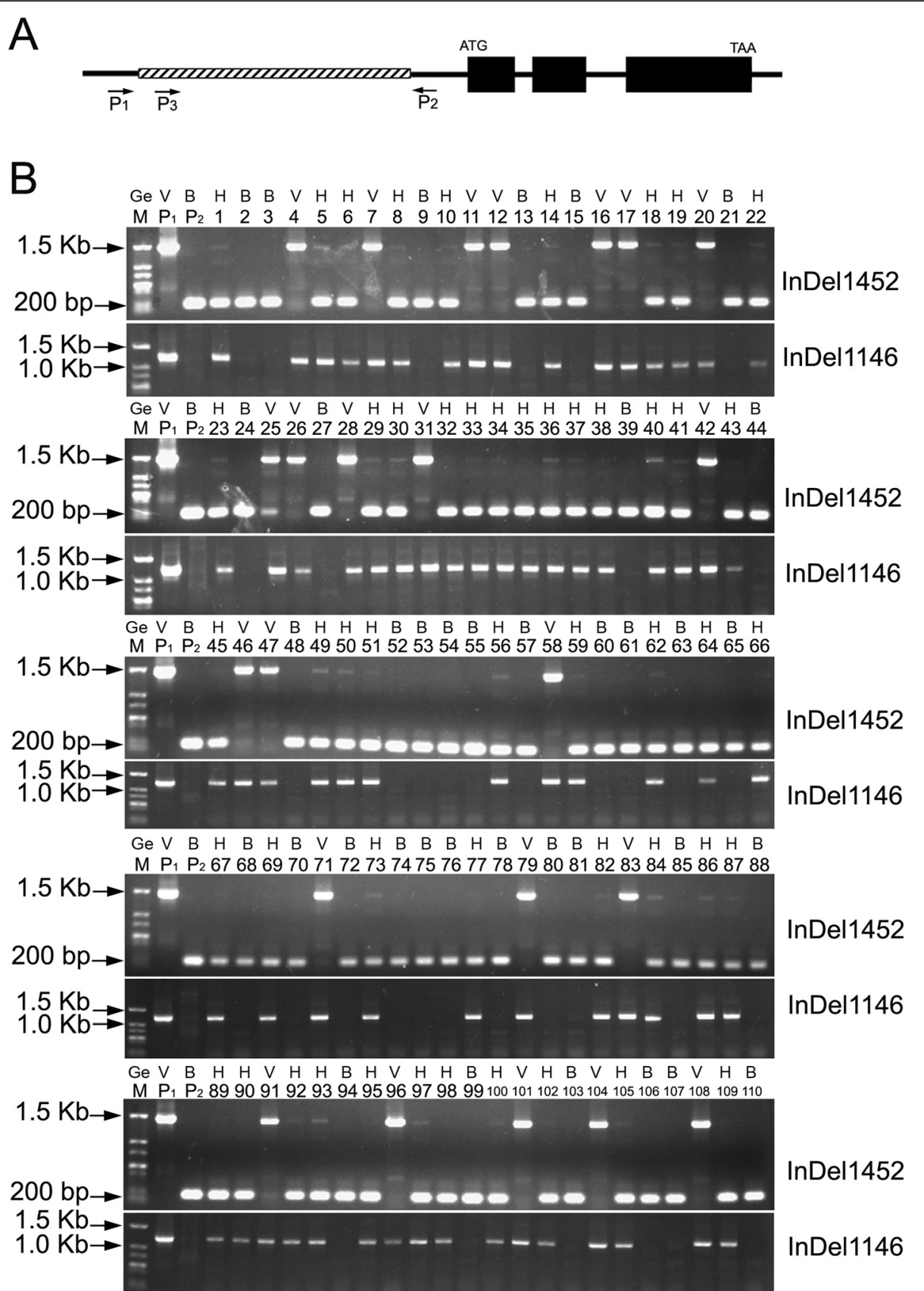

Fig. 4 Structure of the gene Cma_004516 and genotyping of the $F_{2}$ population. a, Schematic diagram of gene structure of Cma_004516. Solid boxes represent coding regions; open boxes with diagonal lines denotes the deleted fragment of the promoter region of Cma_004516 in bush type lines; bold lines, introns or 5', 3'- UTRs. Locations of the indel-markers InDel1452, amplified using the primers $P_{1} / P_{2}$, and InDel1146, amplified using the primers $P_{3} / P_{2}$, are shown. $\mathbf{b}$, Genotyping of the $F_{2}$ population by the two InDel markers. $M$, DNA marker; $P_{1}$, maternal parent Rimu; $P_{2}$, paternal parent SQ026; $1-110$, individual $F_{2}$ lines; $G$, genotypes; $V$, vine type; $B$, bush type

High-density genetic map construction and genome assembly anchoring in C. maxima

The genetic linkage map reported herein is the first map developed using bin markers derived from SNPs in $C$. maxima. Compared to previously reported Cucurbita maps [13, 38-40, 62-65], this map had much higher marker density and fewer gaps, making it the most saturated genetic map in Cucurbita species reported to date. Furthermore, all bin markers used here possess their unique physical locations in the C. maxima reference genome, and are potentially highly transferable among species and even genera, which will facilitate the development of an integrated Cucurbita map by merging different maps $[31,64]$. The map will also allow comparative 

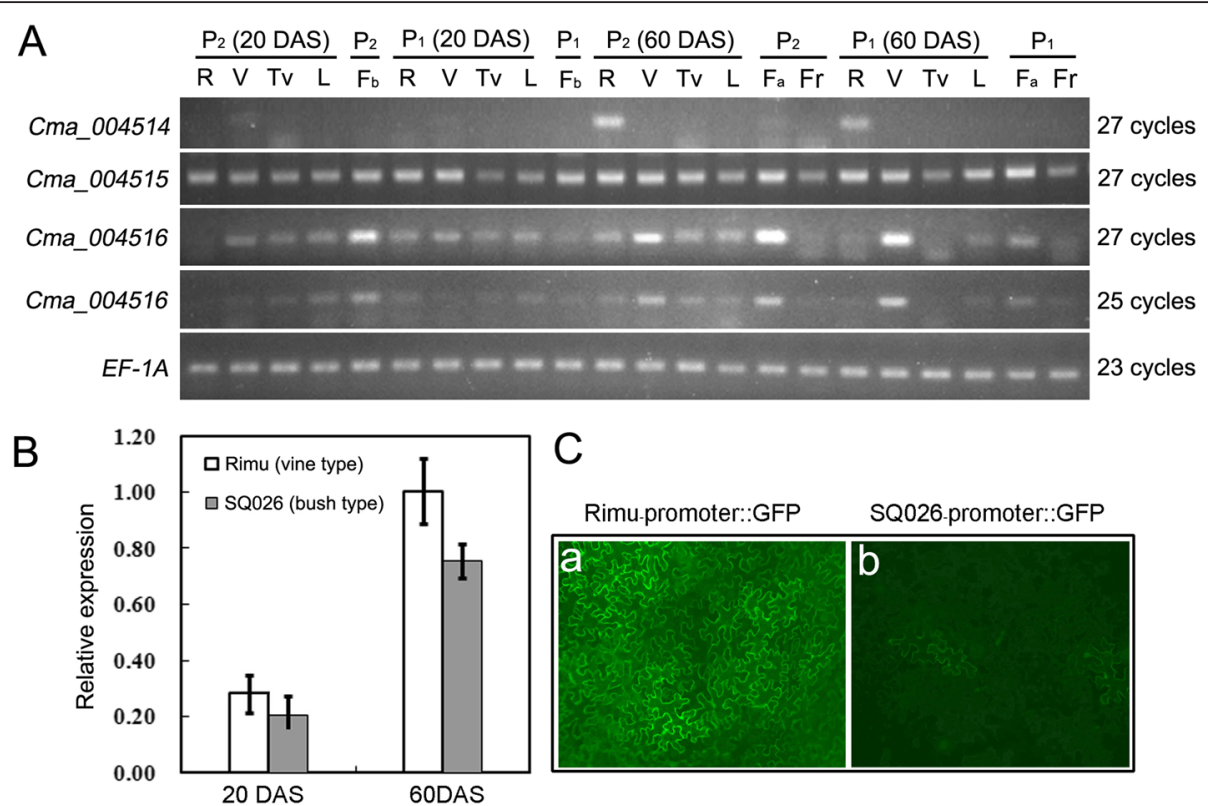

Fig. 5 Expression profiles of Cma_004516 in C. maxima. a, RT-PCR analysis of Cma_004516, Cma_004514 and Cma_004515 mRNA in various tissues. $R$, roots; $V$, vines; TV, tip of the vines; $L$, leaves; $F_{b}$, flowers before anthesis; Fa, flowers after anthesis; Fr, young fruits; DAS, days after sowing. $P_{1}$, maternal parent Rimu; $\mathrm{P}_{2}$, paternal parent SQ026; The right side shows the PCR amplification cycles. EF-1A was used as the internal control. b, Analysis of Cma_004516 gene expression in vines by real-time PCR. Each bar represents an average of three independent reactions, including both biological and technical replicates. Error bars indicated SD. c, Analysis of the activities of the Cma_004516 promoters by transient expression in tobacco leaves. a, promoter of the vine type; b, promoter of the bush type

genetic studies within this genus and may further elucidate the evolution of different species in the genus. However, several large gaps still exist in this genetic map; therefore, additional markers need to be developed in order to get a better covered map.

Distorted segregation was observed in 21 bin markers, which was lower than that reported in maps constructed in C. pepo and from interspecific crosses [13, 62, 63, 65]. Biological segregation distortion can affect a cluster of loci, and form a SDR, which should contain at least three adjacent loci $[66,67]$. Based on this criterion, two SDRs were found, one on LG 3 and the other on LG 12 (Additional file 2: Table S1), and both were located near the end of LGs, possibly due to gametic, zygotic or other selections. Other distortion loci scattered along the LGs $2,4,5,7,11,14,15,16$ and 17 were likely a result of non-biological factors, including the bias introduced in the GBS library construction (e.g., highly repetitive regions are much harder to be cloned and sequenced) and missing data points in SNP calling. Marker inconsistency was also observed in a few regions, mostly caused by duplicated marker loci or segregation distortions [68].

Using this map we successfully anchored 58 scaffolds (71.7 \% of the $271.4 \mathrm{Mb}$ assembled genome) and oriented $183.0 \mathrm{Mb}(67.4 \%)$ of the assembled sequences. Compared to the percentages of anchored and oriented genome sequences in other crop species such as watermelon (93.5\% anchored, $65 \%$ oriented) [11], melon (98.2\%, $90 \%$ [37], cucumber (72.8 \% anchored) [26], cacao (67 \%, $50 \%)$ [69], apple (88\%, $66 \%)$ [70], grape (69\%, $61 \%)$ [71], soybean (97\% anchored) [72] and strawberry (94\% anchored) [73], the percentages of anchored and oriented scaffolds in this study were not high. The major factor that limits successful anchoring and orienting of scaffolds is the map density, which depends on the SNP density and the size of the mapping population. Low sequencing coverage and probably the non-optimal restriction enzyme used in the GBS experiment would result in sparse SNP markers. Therefore, additional markers and a larger mapping population would help to generate a higher density genetic map, which can be used to further facilitate anchoring and ordering of the remaining sequences.

\section{QTL analysis for the bush type vine}

Using the map, a major QTL $q C m B 2$ for dwarfism in $C$. maxima was identified and delimited to a $420-\mathrm{kb}$ physical interval. The QTL contributed to $21.39 \%$ of the phenotypic variation, suggesting the high efficiency in QTL detection using this approach (Table 2, Fig. 3). Among the 104 predicted genes within the QTL region, Cma_004516 encoded a putative gibberellin 20-oxidase and shared 78.5 and $79.1 \%$ amino acid sequence identity with Arabidopsis gibberellin 20-oxidase 2 and Medicago truncatula gibberellin 20-oxidase 1-B, respectively. The physical position of Cma_004516 was very close to the peak of LOD curve for vine length QTL $q \mathrm{CmB2}$ (Fig. 3). The SQ026 (bushy 
parents) allele of Cma_004516 perfectly co-segregated with the dwarf phenotype across the $F_{2}$ and $F_{2: 3}$ populations and a broad range of $C$. maxima germplasm. The large sequence deletion identified in the promoter region of Cma_004516 possibly caused the decreased expression of Cma_004516, which could further decrease the gibberellin level and result in the dwarf phenotype [74, 75]. Therefore, it is reasonable to postulate that Cma_004516 is the candidate gene for dwarfism in C. maxima. However, further experiments are necessary to confirm this hypothesis. In addition, the other two minor QTLs (accounting for about 9.95 and $7.65 \%$ of the phenotypic variance, respectively) also need to be further characterized.

\section{Dwarf gene in C. maxima}

Dwarf and semi-dwarf characteristics are important agronomic traits in crop breeding for higher yield. In Cucurbitaceae, dwarf mutants in cucumber [54], melon [30], squash [44], tropical pumpkin [48, 50] and $C$. maxima [53] have been reported, but little is known about the underlying genetic basis of dwarfism. Incomplete dominance or developmental reversal of dominance was observed in the present study. $F_{1}$ plants of the cross between bush and vine plants resembled the bush parent at the early developmental stages while become more like the vine parent at the late stages (Fig. 2). This is consistent with previous observations in C. pepo and C. maxima, the two species possibly possessing the same dwarf gene $[52,76]$, while it is contradictory to other previously published reports $[44,48,50,53]$, which indicate that the phenotype of bush habit is a completely dominant trait. Singh [51] reported the length of vine was controlled by two pairs of common dominant genes in C. maxima. These inconsistent results are probably due to the fact that bush habits are controlled by multiple different genes or due to the different genetic background of the plant materials used for the studies.

Alternatively, these differences in C. maxima could be caused by developmental dominance reversal of the dwarf gene. We provide support for Cma_004516, which encodes a GA 20-oxidase, as a candidate gene for dwarfism in C. maxima. Gibberellin (GA) deficiency always leads to dwarf or semi-dwarf phenotype [56-59]. The defective GA 20-oxidase genes in rice and Arabidopsis result in the semi-dwarf phenotypes, suggesting that other gene members could supplement GA 20-oxidase activity and contribute partially to the active GA in stem elongation [57, 74]. Therefore, we propose that the developmental reversal of dominance of dwarf gene is caused by the partial overlapping redundancy of GA20-oxidase genes in C. maxima. Cma_004516 is probably critical for active GA at the early developmental stages, but its function could be compensated by other gene members at the late stages (after 5-10 internodes), resulting in behaving dominantly during the early vine development while recessively during the late vine development. Further evaluation of the GA contents in the bushy plants at different development stages and functional characterization of Cma_004516 and its closely related genes should facilitate uncovering the regulatory mechanisms underlying this trait.

\section{Conclusions}

Here, we report the construction of the first high-density linkage map in C. maxima with bin markers developed using the GBS method, which represents the initial reference map of this species. This map successfully assisted in anchoring and orienting the assembled genome scaffolds, and was further used to detect the quantitative loci controlling vine length in C. maxima. A highly possible candidate gene for the major QTL $q C m B 2$ was identified. This study provides deeper understanding of the molecular mechanisms underlying vine variation in C. maxima and will be helpful in accelerating crop improvement in a cost-effective manner through selecting the useful alleles.

\section{Methods}

\section{Plant materials and phenotyping}

Two pumpkin inbred lines, Rimu and SQ026, were used as the parents to generate the $F_{1}$ and $F_{2}$ populations. Rimu is the female parent of 'Shintosa', a popular interspecific hybrid rootstock for watermelon and cucumber used worldwide since the 1950s. The SQ026 is bush type with dwarf vine. The $186 \mathrm{~F}_{2}$ individuals, $30 \mathrm{~F}_{1}$ and 30 parent plants were grown and evaluated in a field nursery at the research farm of Beijing Vegetable Research Centre at Sanya $\left(18.16^{\circ} \mathrm{N}, 109.23^{\circ} \mathrm{E}\right)$ in winter of 2014 . The vine length and internode length of parents, $F_{1}$, and $F_{2}$ were measured at the adult stage (25th node). In total, $185 \mathrm{~F}_{2}$ individuals were evaluated for stem length, due to the loss of an individual resulting from disease.

The $\mathrm{F}_{2: 3}$ families (progeny of the $185 \mathrm{~F}_{2}$ individuals, 30 plants for each family), $201 \mathrm{~F}_{2}$ individuals, Rimu, SQ206, $F_{1}$ and 164 selected pumpkin varieties were grown and evaluated in an experimental field under natural environmental conditions at Yanqing $\left(40.4^{\circ} \mathrm{N}, 115.9^{\circ} \mathrm{E}\right)$ in the summer of 2015. The vines were characterized at the 10th internode.

\section{Genotyping by sequencing}

Genomic DNA from the 186 individuals in the $F_{2}$ population and the two parents was extracted using a Qiagen plant DNAeasy kit (Qiagen, Valencia, CA) with $100 \mathrm{mg}$ fresh leaf tissue after frozen in liquid nitrogen and grounded into fine powders. The methylation-sensitive restriction enzyme ApeKI was used to digest DNA samples. Two 96-plex genotyping-by-sequencing (GBS) libraries were prepared using the protocol described in Elshire 
et al. [41]. The GBS libraries were sequenced on an Illumina HiSeq 2500 system. The TASSEL-GBS pipeline [77] was used to process the GBS sequencing reads for SNP calling. Briefly, raw reads from all samples were combined and collapsed into a master tag list. Only tags occurring at least 10 times were retained and then aligned to the C. maxima genomes using BWA [78] with default parameters. Only alignments with mapping quality $>=2$ were used for SNP calling.

\section{Bin-map construction and scaffold anchoring}

A bin marker comprised SNPs with the consensus segregation pattern, which did not recombine and were thus incorporated in the bin as described in Ren et al. [10]. The bin-markers were then used for map construction using the JoinMap program v4.0 [79]. Linkage groups (LGs) were identified with likelihood odd (LOD) ratios $\geq 5.0$, and marker locations on LGs were graphically displayed using Microsoft Excel via a conditional cell formatting formula and points of disagreement designated as "singletons" were resolved by reassessment of band morphotypes. Scaffolds were then assigned to linkage groups accordingly. When more than one marker had hits on the same scaffold, the scaffold were then oriented on the map.

\section{Detection of dwarf vine QTLs}

Dwarf vine QTLs were identified using the QTL IciMapping v3.1 software, based on the inclusive composite interval mapping (ICIM) model [80]. Threshold values were calculated using 1,000 permutations and QTLs were considered real when ICIM showed the presence of a significant peak at a level of $p<0.05$. The positions of QTLs were derived based on the peaks from the ICIM scans. The percentage of phenotypic variation explained by each QTL was calculated with a single factor regression $\left(R^{2}\right)$. The corresponding additive and dominance effects for each QTL were also estimated.

\section{Genome resequencing of SQ026 and sequence analysis} Genomic DNA was extracted from SQ026 seedlings using the Qiagen plant DNAeasy kit (Qiagen, Valencia, CA). A total of $5 \mu \mathrm{g}$ of genomic DNA was used to construct a paired-end library with insert sizes of around $250 \mathrm{bp}$ according to the manufacturer's instructions (Illumina). The library was sequenced on an Illumina HiSeq 2500 system. The raw Illumina reads were first processed to remove adapters and low quality sequences using Trimmomatic [81] and duplicated reads were collapsed into unique reads. The cleaned unique reads were aligned to the reference Rimu genome using BWA [78] with parameters "-n 0.02 -o 1 -e 2" and the pairedend mapping mode. Only alignments with mapping quality $>16$ were kept. Following alignments, SNPs and small indels were identified as described in Guo et al.
[28] and large structure variations were identified as described in Zhang et al. [82].

\section{Seedlings treated with $\mathrm{GA}_{3}$}

Different concentrations (1, 5, 50, 200, 300 and $600 \mathrm{mg} / \mathrm{L})$ of $\mathrm{GA}_{3}$ solutions were sprayed on 7-day-old seedlings, and control seedlings were sprayed with double distilled water. Each treatment contained 15 lines, and was replicated five times. Seedlings were treated three times a day for 15 days, then used for picture taken, and the length of the first internode was measured.

\section{Phylogenetic tree analysis}

Sequence alignments were carried out with the ClustalX program [83]. A neighbor-joining phylogenetic tree was created using the MEGA5.0 program [84] with 1,000 bootstrap replications.

\section{Expression pattern and promoter activity analysis}

Total RNA was extracted from different tissues at two developmental stages (20 and 60 days after sowing), except flowers and fruits, which were sampled at the 20th internode, using the Trizol reagent (Invitrogen, California, USA) according to the manufacturer's protocol, and treated with RNase-free DNase (TaKaRa Biotechnology Co., Dalian, China) to remove residual genomic DNA. Two microgram of total RNA was used for cDNA synthesis using the PrimeScriptII 1st strand cDNA synthesis kit (TaKaRa, Biotechnology Co., Dalian, China) according to the manufacturer's instructions. Semi-quantitative and quantitative RT-PCR were carried out using the genespecific primers (Additional file 2: Table S7), and EF-1A cDNA was used as the internal control.

A 1,595-bp fragment in the promoter of Cma_004516 in Rimu (from the start codon to the 1,595 bp upstream of the start codon) and a 752-bp fragment in SQ206 (from the start codon to the 2,001 bp upstream of the start codon, and the 1249-bp deletion) were amplified using the specific primer pairs PL-F/P-R and PS-F/P-R, respectively (Additional file 2: Table S7). After digestion with $B a m H I$ and EcoRI, the fragments were subcloned into the binary vector pYBA1332 upstream of the EGFP coding sequence, in place of the CaMV $35 \mathrm{~S}$ promoter. The resulting constructs were then transformed into Agrobacterium tumefaciens strain EHA105 for transient expression in tobacco as described in Sparkes et al. [85].

\section{Availability of supporting data}

The genome sequence and the SNP marker data will be released to the public through the Cucurbit Genomics Database (http://www.icugi.org) when this paper gets accepted. 


\section{Additional files}

Additional file 1 Figure $\mathbf{S 1}$. Recombination bin-map of the $F_{2}$ population. Bin-map consists of 458 bin markers inferred from 1,881 high quality SNPs in the $F_{2}$ population. Red, Rimu genotype; Green, SQ026 genotype; yellow, heterozygote. Figure S2. Distribution of vine length of Rimu, SQ026, $F_{1}$ and $F_{2}$ individuals. Figure S3. $\mathrm{GA}_{3}$ stimulates vine elongation in SQ026 (bush type). Pictures show plants treated with $A, 1 \mathrm{mg} / \mathrm{L} \mathrm{GA}_{3} ; \mathrm{B}, 5 \mathrm{mg} / \mathrm{L} \mathrm{GA}_{3} ; C_{\text {, }}$ $50 \mathrm{mg} / \mathrm{L} \mathrm{GA} ; \mathrm{D}, 200 \mathrm{mg} / \mathrm{L} \mathrm{GA}_{3} ; \mathrm{E}, 300 \mathrm{mg} / \mathrm{L} \mathrm{GA} ; \mathrm{F}, 600 \mathrm{mg} / \mathrm{L} \mathrm{GA}$. CK, plants treated with double distilled water. $G$, Length of the first internodes of the plants after 15-day treatment. *indicates the values are significantly different at $P<0.05$. Figure S4. View of alignments of SQ026 paired-end reads to the Rimu genome around the gene Cma_004516. Figure S5. Sequence alignment of Cma_004516 alleles between bush type and vine type lines. Different sequences are shaded in red, introns are underlined, and the gene translation initiation codon (ATG) and stop codon (TAA) are boxed. Figure S6. Phylogenetic tree of plant GA20-oxidase family members. Nodes are labeled with the percentage of bootstrap iterations. At, Arabidopsis thaliana; Cma, Cucurbita maxima; Cs, Cucumis sativus; Mt, Medicago truncatula; Nt, Nicotiana tabacum; Phpa, Physcomitrella patens; SI, Solanum lycopersicum; Ta, Triticum aestivum; Vv, Vitis vinifera; Zm, Zea mays; GenBank accession numbers are shown in parenthesis (PDF $1751 \mathrm{~kb}$ )

Additional file 2 Table S1. Segregation distortion markers. Table S2. Phenotypic variation of vine length of Rimu, SQ026, $F_{1}$ and $F_{2}$ population. Table S3. Predicted genes in the genome region of the major QTL qCmB2 on scaffold S5. Table S4. Vine phenotypes and genotypes of gene Cma_004516 in $\mathrm{F}_{2: 3}$ families. Table S5. Vine phenotypes and genotypes of gene Cma_004516 in the second $F_{2}$ population. Table S6. Varieties and their vine phenotypes and genotypes of gene Cma_004516. Table S7. Primers used in the present study. (XLSX 43 kb)

\section{Abbreviations}

AFLP: amplified fragment length polymorphism; BWA: burrows-Wheeler Alignment tool; CaMV: cauliflower mosaic virus; cM: centiMorgan; cm: centimeters; DAS: day after sowing; EF-1A: elongation factor 1a gene; EGFP: enhanced green fluorescent protein; GAs: gibberellins;

GBS: genotyping-by-sequencing; ICIM: inclusive composite interval mapping; InDel: insertion/deletion; Kb: kilobases; LG: linkage group; LOD: likelihood of odd ratio; MAF: minimum allele frequency; Mb: million bases; PCR: polymerase chain reaction; qPCR: quantitative poly-merase chain reaction; QTL: quantitative trait locus; SDRs: segregation distortion regions; SNP: single nucleotide polymorphism; TASSEL: trait analysis by association, evolution and linkage; TDFs: transcript derived fragments.

\section{Competing interests}

The authors declare that they have no competing interests.

\section{Authors' contributions}

HL, YX, ZF, HZ and SG conceived and designed the study. GZ collected tissues, prepared DNA samples, and performed QTL mapping, genotyping and gene expression analysis. HS performed sequence analysis and SNP calling. YR, GZ and HS performed bin-map construction and scaffold anchoring. $F Z$ and $Z J$ constructed the $F_{2}$ population and performed the phenotyping. JZ performed the transient gene expression analysis. GZ, HS and ZF wrote and revised the manuscript. All authors read and approved the final manuscript.

\section{Acknowledgements}

This work was supported by grants from the National Natural Science Foundation of China (Project 31101547), Beijing Academy of Agriculture and Forestry Sciences International Cooperation Finance of China (GJHZ2013-), Beijing Academy of Agriculture and Forestry Sciences Special Technology Innovation Building Finance of China (KJCX20140111-8), the Special Fund for Agro-scientific Research in the Public Interest (201303112), and the Twelve-Five Science and Technology Support Program (2012BAD02B03, 2012AA100202-3, 2012BAD50G01).

\section{Author details}

${ }^{1}$ Beijing Vegetable Research Center, BAAFS, Key Laboratory of Biology and Genetic Improvement of Horticultural Crops (North China), Ministry of Agriculture, Beijing Key Laboratory of Vegetable Germplasm Improvement, Beijing 100097, P.R. China. ${ }^{2}$ Boyce Thompson Institute for Plant Research, Cornell University, Ithaca, NY 14853, USA. ${ }^{3}$ USDA-ARS, Robert W. Holley Center for Agriculture and Health, Ithaca, NY 14853, USA.

Received: 9 October 2015 Accepted: 15 December 2015

Published online: 24 December 2015

\section{References}

1. Weeden NF, Robinson RW. Isozyme studies in Cucurbita. In: Bates DM, Robinson RW, Jeffrey C, editors. Biology and utilization of the Cucurbitaceae. NY: Cornell University Press; 1990. p. 51-9.

2. Robinson RW, Decker-Walters DS. Cucurbits. New York: CAB International. Crop Prod Sci Hortic; 1997. p. 226.

3. Ferriol M, Picó B. Pumpkin and Winter Squash. In Handbook of Plant Breeding Vegetables I Part 4. Volume 1. In: Prohens J, Nuez F, editors. NY: Springer; 2008. p. 317-349.

4. Alfawaz MA. Chemical composition and oil characteristics of pumpkin (Cucurbita maxima) seed kernels. Res Bult. 2004;129:5-18.

5. Stevenson DG, Eller FJ, Wang L, Jane JL, Wang T, Inglett GE. Oil tocopherol content and composition of pumpkin seed oil in 12 cultivars. J Agric Food Chem. 2007:55:4005-13.

6. Xing WW, Li L, Gao P, Li H, Shao QS, Shu S, et al. Effects of grafting with pumpkin rootstock on carbohydrate metabolism in cucumber seedlings under $\mathrm{Ca}\left(\mathrm{NO}_{3}\right)_{2}$ stress. Plant Physiol Bioch. 2015;87:124-32.

7. Wimer J, Inglis D, Miles C. Evaluating grafted watermelon for verticillium wilt severity, yield, and fruit Quality in washington state. HortSci. 2015;50(9):1332-7.

8. Yassin $\mathrm{SH}$. Reiview on role of grafting on yield and quality of selected fruit vegetables. Global J Sci Front Res. 2015;15(1). http://www.journalofscience. org/index.php/GJSFR/article/view/1492/1353.

9. Deleu W, Esteras C, Roig C, González-To M, Fernández-Silva I, Blanca J, et al. A set of EST-SNP for map saturation and cultivar identification in melon. BMC Plant Biol. 2009;9:90.

10. Ren Y, Zhang Z, Liu J, Staub JE, Han Y, Cheng Z, et al. An integrated genetic and cytogenetic map of the cucumber genome. PLoS One. 2009:4:e5795.

11. Ren $Y$, Zhao H, Kou Q, Jiang J, Guo S, Zhang H, et al. A high resolution genetic map anchoring scaffolds of the sequenced watermelon genome. PLoS One. 2012;7(1):e29453.

12. Diaz A, Fergany M, Formisano G, Ziarsolo P, Blanca J, Fei Z, et al. A consensus linkage map for molecular markers and Quantitative Trait Loci associated with economically important traits in melon (Cucumis melo L.). BMC Plant Biol. 2011;11:111.

13. Esteras C, Gómez P, Monforte AJ, Blanca J, Vicente-Dólera N, Roig C, et al. High-throughput SNP genotyping in Cucurbita pepo for map construction and quantitative trait loci mapping. BMC Genomics. 2012;13:80.

14. Wei Q, Wang Y, Qin X, Zhang Y, Zhang Z, Wang J, et al. An SNP-based saturated genetic map and QTL analysis of fruit-related traits in cucumber using specific-length amplified fragment (SLAF) sequencing. BMC Genomics. 2014:15:1158.

15. Wechter WP, Levi A, Harris KR, Davis AR, Fei Z, Katzir N, et al. Gene expression in developing watermelon fruit. BMC Genomics. 2008:9:275.

16. Mascarell-Creus A, Cañizares J, Vilarrasa J, Mora-García S, Blanca J, González-lbeas D, et al. An oligo-based microarray offers novel transcriptomic approaches for the analysis of pathogen resistance and fruit quality traits in melon (Cucumis melo L.). BMC Genomics. 2009;10:467.

17. Dahmani-Mardas F, Troadec C, Boualem A, Lévêque S, Alsadon AA, Aldoss AA, et al. Engineering melon plants with improved fruit shelf life using the TILLING approach. PLoS One. 2010;5(12):e15776.

18. González M, Xu M, Esteras C, Roig C, Monforte AJ, Troadec C. Towards a TILLING platform for functional genomics in Piel de Sapo melons. BMC Res Notes. 2011;4:289.

19. Fraenkel R, Kovalski I, Troadec C, Bendahmane A, Perl-Treves R. A TILLING population for cucumber forward and reverse genetics. Cucurbitaceae 2012, Proceedings of the Xth EUCARPIA meeting on genetics and breeding of Cucurbitaceae; 2012 Oct 598-603; Antalya, Turkey.

20. Guo S, Zheng Y, Joung JG, Liu S, Zhang Z, Crasta OR, et al. Transcriptome sequencing and comparative analysis of cucumber flowers with different sex types. BMC Genomics. 2010;11:384. 
21. Guo SG, Liu JG, Zheng Y, Huang MY, Zhang HY, Gong GY, et al. Characterization of transcriptome dynamics during watermelon fruit development: sequencing, assembly, annotation and gene expression profiles. BMC Genomics. 2011;12:454.

22. Blanca J, Cañizares J, Ziarsolo P, Esteras C, Mir G, Nuez F, et al. Melon transcriptome characterization. SSRs and SNPs discovery for high throughput genotyping across the species. Plant Genome. 2011;4(2):118-31.

23. Blanca J, Esteras C, Ziarsolo P, Pe'rez D, Fernández V, Collado C Transcriptome sequencing for SNP discovery across Cucumis melo. BMC Genomics. 2012;13:280.

24. Ando K, Carr KM, Grumet R. Transcriptome analyses of early cucumber fruit growth identifies distinct gene modules associated with phases of development. BMC Genomics. 2012;13:518.

25. Wu TQ, Luo SB, Wang R, Zhong YJ, Xu XM, Lin YE, et al. The first Illuminabased de novo transcriptome sequencing and analysis of pumpkin (Cucurbita moschata Duch.) and SSR marker development. Mol Breeding. 2014;34:1437-47.

26. Huang $S$, Li R, Zhang Z, Li L, Gu X, Fan W, et al. The genome of the cucumber, Cucumis sativus L. Nat Genet. 2009:41:1275-81.

27. Garcia-Mas J, Benjak A, Sanseverino W, Bourgeois M, Mir G, González VM, et al. The genome of melon (Cucumis melo L.). Proc Natl Acad Sci U S A. 2012;109(29):11872-7.

28. Guo S, Zhang J, Sun H, Salse J, Lucas WJ, Zhang H, et al. The draft genome of watermelon (Citrullus lanatus) and resequencing of 20 diverse accessions. Nat Genet. 2013;45(1):51-8.

29. Yang LM, Li DW, Li YH, Gu XF, Huang SW, Garcia-Mas J, et al. A 1,681-locus consensus genetic map of cultivated cucumber including 67 NB-LRR resistance gene homolog and ten gene loci. BMC Plant Biol. 2013;13:53.

30. Hwang JY, Oh JY, Kim ZH, Staub JE, Chung SM, Park YH. Fine genetic mapping of a locus controlling short internode length in melon (Cucumis melo L.). Mol Breeding. 2014;34(3):949-61.

31. Ren Y, McGregor C, Zhang Y, Gong G, Zhang H, Guo S, et al. An integrated genetic map based on four mapping populations and quantitative trait loci associated with economically important traits in watermelon (Citrullus lanatus). BMC Plant Biol. 2014;14:33.

32. Shang $Y, M a Y$, Zhou $Y$, Zhang $H$, Duan $L$, Chen $H$, et al. Biosynthesis, regulation, and domestication of bitterness in cucumber. Science. 2014;28:1084-8.

33. Wehner TC, Mitchell SE, Reddy UK. Single nucleotide polymorphisms generated by genotyping by sequencing to characterize genome-wide diversity, linkage disequilibrium, and selective sweeps in cultivated watermelon. BMC Genomics. 2014;15:767.

34. Bhawna MZ, Abdin L, Arya L, Verma M. Transferability of cucumber microsatellite markers used for phylogenetic analysis and population structure study in bottle gourd (Lagenaria siceraria (Mol.) Standl.). Appl Biochem Biotechnol. 2015;175(4):2206-23.

35. Xanthopoulou A, Ganopoulos I, Kalivas A, Nianiou-Obeidat I, Ralli P, Moysiadis T, et al. Comparative analysis of genetic diversity in Greek Genebank collection of summer squash (Cucurbita pepo) landraces using start codon targeted (SCOT) polymorphism and ISSR markers. Aust J Crop Sci. 2015;9(1):4.

36. Xanthopoulou A, Ganopoulos I, Tsaballa A, Nianiou-Obeidat I, Kalivas A, Tsaftaris A, et al. Summer squash identification by High-Resolution-Melting (HRM) analysis using gene-based EST-SSR molecular markers. Plant Mol Biol Rep. 2014;32(2):395-405.

37. Argyris JM, Ruiz-Herrera A, Madriz-Masis P, Sanseverino W, Morata J, Pujol M, et al. Use of targeted SNP selection for an improved anchoring of the melon (Cucumis melo L.) scaffold genome assembly. BMC Genomics. 2015;16(1):4

38. Weeden NF, Robinson RW. Allozyme segregation ratios in the interspecific cross Cucurbita maxima $\times$ C. ecuadorensis suggest that hybrid breakdown is not caused by minor alteration in chromosome structure. Genetics. 1986:114:593-609.

39. Singh AK, Singh R, Weeden NF, Robinson RW, Singh NK. A linkage map for Cucurbita maxima based on Randomly Amplified Polymorphic DNA (RAPD) markers. Indian J Horticulture. 2011;68(1):44-50.

40. Ge Y, Li X, Yang XX, Cui CS, Qu SP. Genetic linkage map of Cucurbite maxima with molecular and morphological markers. Genet Mol Res. 2015;14(2):5480-4.

41. Elshire RJ, Glaubitz JC, Sun Q, Poland JA, Kawamoto K, Buckler ES, et al. A robust, simple genotyping-by-sequencing (GBS) approach for high diversity species. PLoS One. 2011;6(5):e19379.
42. Sandlin K, Prothro J, Heesacker A, Khalilian N, Okashah R, Xiang W, et al. Comparative mapping in watermelon [Citrullus lanatus (Thunb.) Matsum. et Nakai]. Theor Appl Genet. 2012;125(8):1603-18.

43. Talukder S, Babar M, Vijayalakshmi K, Poland J, Prasad P, Bowden R, et al. Mapping QTL for the traits associated with heat tolerance in wheat (Triticum aestivum L.). BMC Genet. 2014;15(1):97.

44. Edelstein $\mathrm{M}$, Paris $\mathrm{HS}$, Nerson $\mathrm{H}$. Dominance of bush growth habit in spaghetti squash (Cucurbita pepo). Euphytica. 1989;43:253-7.

45. Paris HS, Edelstein M. Same gene for Bush growth habit in Cucurbita pepo ssp. pepo as in C. pepo ssp. Ovifera. Cucurbit Genet Coop Rep. 2001;24:80-1.

46. Cao JS, Yu HF, Ye WZ, Yu XL, Liu LC, Wang YQ, et al. Identification and characterisation of a gibberellin-related dwarf mutant in pumpkin (Cucurbita moschata). J Hortic Sci Biotechnol. 2005;80(1):29-31.

47. Li YL, Li HZ, Cui CS, Zhang HY, Gong GY. Molecular markers linked to the dwarf gene in squash. J Agr Biotech. 2007;15(2):279-82.

48. Wu T, Zhou JH, Zhang YF, Cao JS. Characterization and inheritance of a bush-type in tropical pumpkin (Cucurbita moschata Duchesne). Sci Hortic. 2007;114(1):1-4.

49. Wu T, Cao JS. Molecular cloning and expression of a bush related CmV 1 gene in tropical pumpkin. Mol Bio Rep. 2010;37:649-52.

50. Wang SH, Li HZ, Zhang ZH, He J, Jia CC, Zhang F, et al. Comparative Mapping of the Dwarf Gene Bu from Tropical Pumpkin (Cucurbita moschata Duchesne). Acta Horticulturae Sinica. 2011;38(1):95-100.

51. Singh D. Inheritance of certain economic characters in the squash, Cucurbita maxima Duch. Minnesota. Minn Agr Exp Sta Tech Bul. 1949;186:30.

52. Denna DW, Munger HM. Morphology of the bush and vine habits and the allelism of the bush genes in Cucurbita maxima and C. pepo squash. Proc Am Soc Hortic Sci. 1963;82:370-7.

53. Wang $R$, Huang $H$, Lin $Y$, Chen $Q$, Liang $Z$. Wu, $T$. Genetic and gene expression analysis of $\mathrm{dm} 1$, a dwarf mutant from Cucurbita maxima Duch. ex Lam, based on the AFLP method. Can J Plant Sci. 2014;94(2): 293-302.

54. Li Y, Yang L, Pathak M, Li D, He X, Weng Y. Fine genetic mapping of cp: a recessive gene for compact (dwarf) plant architecture in cucumber, Cucumis sativus L. Theor Appl Genet. 2011;12:973-83.

55. Gao ZY, Zhao SC, He WM, Guo LB, Peng YL, Wang JJ, et al. Dissecting yieldassociated loci in super hybrid rice by resequencing recombinant inbred lines and improving parental genome sequences. Proc Natl Acad Sci U S A. 2013;110(35):14492-7.

56. Olszewski N, Sun T, Gubler F. Gibberellin signaling: biosynthesis, catabolism, and response pathways. Plant Cell. 2002;14:S61-80.

57. Spielmeyer W, Ellis MH, Chandler PM. Semidwarf (sd-1), "green revolution" rice, contains a defective gibberellin 20-oxidase gene. Proc Natl Acad Sci U S A. 2002:99:9043-8.

58. Sakamoto T, Miura K, Itoh H, Tatsumi T, Ueguchi-Tanaka M, Ishiyama K, et al. An overview of gibberellin metabolism enzyme genes and their related mutants in rice. Plant Physiol. 2004;134:1642-53.

59. Peter H, Stephen GT. Gibberellin biosynthesis and its regulation. Biochem J. 2012;444:11-25.

60. Yamaguchi S. Gibberellin metabolism and its regulation. Annu Rev Plant Biol. 2008:59:225-51.

61. Farrow SC, Facchini PJ. Functional diversity of 2-oxoglutarate/Fe (II)dependent dioxygenases in plant metabolism. Front Plant Sci. 2014;5:524.

62. Brown RN, Myers JR. A genetic map of squash (Cucurbita sp.) with randomly amplified polymorphic DNA markers and morphological markers. J Am Soc Hortic Sci. 2002;127(4):568-75.

63. Zraidi A, Stift G, Pachner M, Shojaeiyan A, Gong L, Lelley T. A consensus map for Cucurbita pepo. Mol Breeding. 2007;20(4):375-88.

64. Gong L, Pachner M, Kalai K, Lelley T. SSR-based genetic linkage map of Cucurbita moschata and its synteny with Cucurbita pepo. Genome. 2008; 51(11):878-87.

65. Gong L, Stift G, Kofler R, Pachner M, Lelley T. Microsatellites for the genus Cucurbita and an SSR-based genetic linkage map of Cucurbita pepo L. Theor Appl Genet. 2008;117(1):37-48.

66. Paillard S, Schnurbusch T, Winzeler M, Messmer M, Sourdille P, Abderhalden O, et al. An integrative genetic linkage map of winter wheat (Triticum aestivum L.) Theor Appl Genet. 2003;107:1235-42.

67. Alheit KV, Reif JC, Maurer HP, Hahn V, Weissmann EA, Miedaner T, et al. Detection of segregation distortion loci in triticale ( $\times$ Triticosecale Wittmack) based on a high-density DArT marker consensus genetic linkage map. BMC Genomics. 2011;12:380 
68. Francki MG, Walker E, Crawford AC, Broughton S, Ohm HW, Barclay I, et al. Comparison of genetic and cytogenetic maps of hexaploid wheat (Triticum aestivum L.) using SSR and DArT markers. Mol Genet Genomics. 2009;281: $181-91$.

69. Argout X, Salse J, Aury JM, Guiltinan MJ, Droc G, Gouzy J, et al. The genome of Theobroma cacao. Nat Genet. 2010:43:101-8.

70. Velasco R, Zharkikh A, Affourtit J, Dhingra A, Cestaro A, Kalyanaraman A, et al. The genome of the domesticated apple (Malus $\times$ domestica Borkh.) Nat Genet. 2010;42:833-9.

71. Jaillon O, Aury JM, Noel B, Policriti A, Clepet C, Casagrande A, et al. The grapevine genome sequence suggests ancestral hexaploidization in major angiosperm phyla. Nature. 2007:449:463-7.

72. Hyten DL, Cannon SB, Song Q, Weeks N, Fickus EW, Shoemaker RC, et al. High-throughput SNP discovery through deep resequencing of a reduced representation library to anchor and orient scaffolds in the soybean whole genome sequence. BMC Genomics. 2010;11:38.

73. Shulaev V, Sargent DJ, Crowhurst RN, Mockler TC, Folkerts O, Delcher AL, et al. The genome of woodland strawberry (Fragaria vesca). Nat Genet 2010:43:109-16.

74. Xu YL, Li L, Wu K, Peeters AJ, Gage DA, Zeevaart JA. The GA5 locus of Arabidopsis thaliana encodes a multifunctional gibberellin 20-oxidase: molecular cloning and functional expression. Proc Natl Acad Sci U S A. 1995;92(14):6640-4.

75. Qiao F, Zhao KJ. The influence of RNAi targeting of OsGA200x2 gene on plant height in rice. Plant Mol Bio Rep. 2011;29(4):952-60.

76. Shifriss O. Developmental reversal of dominance in Cucurbita pepo. Proc Amer Soc Hort Sci. 1947;50:330-46.

77. Glaubitz JC, Casstevens TM, Lu F, Harriman J, Elshire RJ, Sun Q, et al. TASSELGBS: A High Capacity Genotyping by Sequencing Analysis Pipeline. PLoS One. 2014;9(2):e90346.

78. Li H, Durbin R. Fast and accurate short read alignment with BurrowsWheeler transform. Bioinformatics. 2009;25(14):1754-60.

79. Van Ooijen JW. Joinmap 4: Software for the calculation of genetic linkage maps in experimental populations. Kyazma BV, Wageningen, Netherlands. 2006.

80. Li H, Ye G, Wang J. A modified algorithm for the improvement of composite interval mapping. Genetics. 2007:175:361-74.

81. Bolger AM, Lohse M, Usadel B. Trimmomatic: a flexible trimmer for Illumina sequence data. Bioinformatics. 2014:30:2114-20.

82. Zhang Z, Mao L, Chen H, Bu F, Li G, Sun J, et al. Genome-wide mapping of structural variations reveals a copy number variant that determines reproductive morphology in cucumber. Plant Cell. 2015;27:1595-604.

83. Larkin MA, Blackshields G, Brown NP, Chenna R, McGettigan PA, McWilliam $H$, et al. Clustal W and Clustal X version 2.0. Bioinformatics. 2007;23(21): 2947-8.

84. Tamura K, Peterson D, Peterson N, Stecher G, Nei M, Kumar S. MEGA5: molecular evolutionary genetics analysis using maximum likelihood, evolutionary distance, and maximum parsimony methods. Mol Biol Evol. 2011;28:2731-9.

85. Sparkes IA, Runions J, Kearns A, Hawes C. Rapid, transient expression of fluorescent fusion proteins in tobacco plants and generation of stably transformed plants. Nat Protoc. 2006;1(4):2019-25.

\section{Submit your next manuscript to BioMed Central and we will help you at every step:}

- We accept pre-submission inquiries

- Our selector tool helps you to find the most relevant journal

- We provide round the clock customer support

- Convenient online submission

- Thorough peer review

- Inclusion in PubMed and all major indexing services

- Maximum visibility for your research

Submit your manuscript at www.biomedcentral.com/submit

) Biomed Central 